\title{
Buchbesprechungen - Book Reviews - Livres Nouveaux
}

P. Porcher, H.-U. Stössel und P. Maínguet: Klinische Radiologie des Magens und des Zwölffingerdarms. G. Thieme, Stuttgart 1959. XII + 264 S., 260 Abb. in 468

Einzeldarstellungen. DM 72.-.

Das von zwei ausländischen Schülern Porcher, s zusammengestellte Buch will der Technik und den Erkenntnissen der Pariser Schule eine bessere Verbreitung auch im deutschen Sprachgebiet verschaffen. Porcher bedauert im Vorwort die scheinbar geringe Resonanz der Arbeiten seiner Schule im ausländischen Schrifttum.

In einem 1. Teil wird mit aller Ausführlichkeit die Standard-Untersuchung be-schrieben. Es wird auch auf den Wert der Aufnahmen als Dokument bei normalen oder scheinbar normalen Befunden zu Recht hingewiesen. Wenn aber eine Routine-untersuchung 16-20 Bilder für Magen und Duodenum erfordert, dann mag dies für Schulzwecke notwendig sein, kaum aber in der Praxis. Es erscheint dem Referenten, daß der Wert der eng ausgeblendeten gezielten $\mathrm{Dl}$ - heute durch den Bildverstärker noch verbessert - zu wenig betont wird. Daß bei Verdacht auf Wandstarre im speziellen Fall mit Bildern in verschiedenen Phasen und Strahlenrichtungen nicht 136 Buchbesprechungen - Book Reviews - Livres Nouveaux gespart werden darf, ist natiirlich klar. Um diesem Vorgehen weite Verbreitung zu schaffen, müßte doch eine höhere diagnostische Ausbeute bewiesen sein.

Erstaunlich ist, daß die Beurteilung des ösophags immer noch vorgängig der Magenbeurteilung beschrieben wird, wo doch die genaue Ösophaguntersuchung in verschiedenen Lagen eine Bariumbreimenge benötigt, welche die anschließende Magenschleimhautbeurteilung bereits verunmöglicht. Der Osophag und die Hiatus-region werden gewiß mit Vorteil erst im Verlaufe der Untersuchung und im Über-gang in horizontale Lage geprüft.

Anschließend werden die Anpassungen der Untersuchung an spezielle Frage-stellungen und spezielle Lokalisation eines organischen Prozesses geschildert, wobei bei Darstellung der Früherfassung des Magencarcinoms die Anschauungen und Bilder von Gutmann verwendet werden. In Anbetracht der weitausholenden Darstellung der übrigen Abschnitte ist die Behandlung der Spätuntersuchung des operierten Magens relativ kurz gefaßt. Gerade hier spielt die Anpassung der Unter-suchungstechnik eine große Rolle. Bei der Untersuchung einer Pylorusstenose ver-mißt man die Erwähnung der Sondermethode nach Buchtala. In persönlicher Erfahrung hat sich dieses Verfahren der Anwendung von Morphin überlegen gezeigt. In einem 2. Teil wird ausführlich über die von Porcher seit 1941 angewandte und in vielen Arbeiten und Kongreßreferaten mitgeteilte Pharmako-Radiographie mit Morphin und Atropin berichtet. Wer die Vorteile dieser Methode kennen gelernt hat und sie in speziellen Fallen kritisch anwendet, wird nicht mehr auf diese Möglichkeit einer zusätzlichen Abklärung verzichten wollen. Auf die seltene Peristaltikblockie-rung durch Morphin sowie auf die Maskierung diskreter Starren bei nur auf die Mucosa beschränkten Infiltrationen, wird hingewiesen. Die Bilder und kasuistischen Mitteilungen belegen den Wert des Verfahrens. In einem 3. Teil wird die Parietographie (Magenwanddarstellung durch Pneumo-peritoneum und Luftaufblähung des Magens) beschrieben. Das Bildmaterial ist schön zusammengestellt, doch 
muß man mit Ausnahme der Fornixregion sagen, daß die meisten Befunde auch ohne Parietographie wohl zu deuten wären.

In einem letzten kurzen Abschnitt werden noch die Vorteile der Röntgenkine-matographie geschildert. Auch hier dürfte der größte Vorteil darin liegen, daß der Befund beliebig oft reproduziert und somit besser analysiert werden kann ohne weitere Strahlenbelastung des Patienten. Auch ist damit die Demonstration von Dl-Befunden einem größeren Personenkreis ermöglicht.

Das Buch bietet sicher eine gute Einführung für den Lernenden in die Untersuchungstechnik und die Ergebnisse der Schule von Porcher. Der Erfahrene wird daraus Anregungen ziehen und sich zu kritischer Überprüfung seiner eigenen Untersuchungstechnik veranlaßt sehen. Möge das begeisterte Vorwort von H. H. Berg dazu beitragen, daß das Buch auch die gewünschte Verbreitung findet und zur Überbrückung gegensätzlicher Anschauungen führen kann. S. Laser, Basel Bouvíer, C: La musculature striée des cirrhotiques. These de Geneve 1959. The author describes a peculiar type of focal, degenerative lesion found in skeletal muscle obtained from 300 cirrhotic, non cachetic, hypergammaglobulinaemic patients. These lesions are not secondary to peripheral polyneuritis, and are easily distinguished from the nodular myotitis of , collagen diseases”, in which the vascular involvement is immediately apparent. The metabolic origin of such tissue modification is discussed, particularly in relation to the constant association with hyper- 